\title{
Development of an electronic assistive walking device
}

\author{
CRISTINA REYNDERS-FREDERIX ${ }^{*}$, PETER REYNDERS-FREDERIX ${ }^{2}$, \\ INNOCENTI BERNARDO ${ }^{3}$, BERTEANU MIHAI ${ }^{4}$
}

\author{
${ }^{1}$ University Hospitals Brussels, campus Saint-Pierre, Université Libre de Bruxelles, Rue \\ haute 322, 1000 Brussels, Belgium \\ ${ }^{2}$ University Hospitals Brussels, campus Brugmann, Université Libre de Bruxelles, Place \\ Arthur Vangehuchten 4, 1020 Brussels, Belgium \\ ${ }^{3}$ BEAMS, (Bio Electro and Mechanical Systems) Université Libre de Brussels, Rue Franklin \\ Rooseveltlaan 50, 1050 Bruxelles, Belgium \\ ${ }^{4}$ Department of Revalidation \& Physiotherapy, Carol Davila University of Medicine and \\ Pharmacy, Mărăşti Av, No. 17, $1^{\text {st }}$ District, Postal Code 011416, Bucharest, Romania
}

\begin{abstract}
Aims: The development of an intelligent assistive walking device to assess mechanical parameters during gait.

Methods: We describe the development and testing of a wireless electronic walking device. The walking device was tested by nine healthy volunteers. To isolate axial loading during walking we set up a full Wheatstone bridge at the surface of the crutch shaft. A triaxial accelerometer and a tri-axial accelerometer is used for determining the speed of the crutch in the sagittal plane. The pitch and roll angles in the frontal plane were measured using a tri-axial accelerometer and a tri-axial gyroscope. The data were retrieved and send by Blue tooth. Graphic output was written in PyCharm (Python).

Results: Handling of the electronic walking device was efficient although the lack of sufficient encasing of the wires and hardware makes this crutch for the moment only useful in the laboratory. There were no safety issues.

Conclusions: Using the three parameters obtained from the wireless connected forearm crutch, we hope to create in future an algorithm that will help us in predicting the healing of orthopedic patients with lower limb injuries.
\end{abstract}

Keywords Rehabilitation, weight bearing, instrumented crutches.

To cite this article: REYNDERS FC, REYNDERS FP, BERNARDO I, BERTEANU MIHAI B. Development of an electronic assistive walking device. Rom Biotechnol Lett. 2020; 25(5): 1992-1997. DOI: 10.25083/rbl/25.5/1992.1997

* Corresponding author: CRISTINA REYNDERS-FREDERIX, University Hospitals Brussels, Belgium E-mail: Cristina reynders-frederix@ stpierre-bru.be / cristina.reynders@ gmail.com

Address for correspondence: Department of Rehabilitation Medicine, Elias University Hospital, Mărăşti Av, No. 17, $1^{\text {st }}$ District, Postal Code 011416, Bucharest, Romania, Phone: 0032473361420 


\section{Introduction}

In recent time a surge of elderly with orthopedic lesions to lower limbs emerge (Court-Brown, 2014).

The fact of an increasing number of frail persons with limb injuries puts a serious burden on the social systems of most of the western countries confronted with that problem (RÜEDI TP, 2000).

Typical example of an osteoporotic fracture is the hip fracture in the elderly patient. Two decades ago these patients stayed for months in the hospital with a high mortality and morbidity rate as a consequence to the prolonged inclined position in bed. Balanced traction with skeletal traction was often seen as an accepted method of treating these enigmatic fractures. Bedsores, cardiac and or respiratory failure was often the end stage of these patients (ARIZA-VEGA P., 2015).

The economic burden of this type treatment protocol was substantial.

Hence the need for treatment protocols to get these patient as quick as possible out of bed. Revalidation of these patients became important. Around six million people in the US are crutch users, and more than 575,000 patients in the USA are prescribed crutches each year (KAYE, 2000).

Walking aids are often used as an essential rehabilitation tool to help patients in their functional recovery. Often, the crutch is the last stage in the rehabilitation program after lower limb orthopedic surgery. (RASOULI, 2019). Although crutches are often prescribed by a physiotherapist to facilitate post-operative walking, the exact knowledge of the forces acting on the affected limb in a certain clinical situation are difficult to obtain (RASOULI, 2019; TONUTTI, 2015), however, this information is important as instrument used to monitor the progression of functionality and proprioception during rehabilitation are missing (TONUTTI, 2015; MERRETT, 2010; MERRETT, 2009). Radiographs provide a lot of information on the healing process. For example, often patients perform poor on a functional level, even with an excellent radiological outcome. A typical example is total knee arthroplasty, which does not give satisfaction in $20 \%$ of the patients. In these cases radiographs look good, but the patient is lacking functional recovery and has persistent pain and muscle wasting (KAHLENBERG, 2018).

The aim of this project was to develop an instrumented wireless crutch that records force, pitch and roll movement in a plane perpendicular to the line of movement and angular speed of the crutch in a sagittal plane, in line with the patient's progression.

In part, this work is inspired by previous studies that developed a similar tool (TONUTTI, 2015; MERRETT, 2010; MERRETT, 2009; SARDINI, 2014).

\section{Methods and Materials}

Between 2015 and 2018 the departments of Biomedical Engineering, Physiotherapy and Orthopedic Surgery of the Free University of Brussels, developed a wireless electric Lofstrand crutch (MERRETT, 2009; SARDINI, 2014; LOFSTRAND, 1955). In contrast to these previous studies, we wanted to measure direct or indirect the actual loading of the injured limb and crutch. Often the patient is instructed to put weight on the injured leg in percentage of his total weight, which is subjective for the patient and care giver. In our setting, with real load recording, no need for audible biofeedback was needed.

Table 1.

\begin{tabular}{|c|c|c|c|c|c|c|c|c|c|c|}
\hline $\mathrm{N}^{\circ}$ & F/M & Age & $\mathrm{W}$ & $\mathrm{H}$ & Sh & $\mathrm{R}$ & $\mathrm{L}$ & $\mathrm{F}$ & $\mathrm{Hz}$ & $\mathrm{P}$ \\
\hline \multirow[t]{2}{*}{1} & 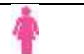 & $39 y$ & 52 & 1.77 & 34 & $\mathrm{x}$ & & 17 & 5.7 & 0.01 \\
\hline & & & & & & & $\mathrm{X}$ & 15 & 5.9 & 0.25 \\
\hline \multirow[t]{2}{*}{2} & \% & $39 y$ & 52 & 1.77 & 34 & $\mathrm{x}$ & & 17 & 3.8 & 2 \\
\hline & & & & & & & $\mathrm{X}$ & 17 & 4.2 & 1.15 \\
\hline \multirow[t]{2}{*}{3} & in & $63 y$ & 85 & 1.88 & 45 & $\mathrm{x}$ & & 19 & 5.4 & 8.1 \\
\hline & & & & & & & $\mathrm{X}$ & 30 & 5.4 & 1.0 \\
\hline \multirow[t]{2}{*}{4} & $\overline{11}$ & $63 y$ & 85 & 1.88 & 45 & $\mathrm{x}$ & & 25 & 5.2 & 12.6 \\
\hline & & & & & & & $\mathrm{x}$ & 37 & 5.2 & 79 \\
\hline \multirow[t]{2}{*}{5} & 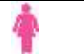 & $32 y$ & 46 & 1.56 & 36 & & $\mathrm{x}$ & 40 & 4.7 & 0.27 \\
\hline & & & & & & $\mathrm{x}$ & & 40 & 4.7 & 1.2 \\
\hline \multirow[t]{2}{*}{6} & 8 & $27 y$ & 51 & 1.56 & 37 & $\mathrm{x}$ & & 25 & 3.5 & 1.16 \\
\hline & & & & & & & $\mathrm{x}$ & 68 & 4.1 & 7.3 \\
\hline 7 & 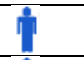 & $31 \mathrm{y}$ & 85 & 1.88 & 45 & $\mathrm{x}$ & & 170 & 6.5 & 0.59 \\
\hline \multirow[t]{2}{*}{8} & $\pi$ & $27 y$ & 76 & 1.82 & 43 & $\mathrm{x}$ & & 85 & 5.5 & 0.63 \\
\hline & & & & & & & $\mathrm{x}$ & 126 & 5.2 & 0.08 \\
\hline \multirow[t]{2}{*}{9} & $\pi$ & $25 y$ & 72 & 1.71 & 44 & $\mathrm{x}$ & & 80 & 4.3 & 0.01 \\
\hline & & & & & & & $\mathrm{x}$ & 272 & 4.3 & 1.3 \\
\hline
\end{tabular}

Vol: volunteer. Sh: shoe size W: weight in kilo's H: height in meters Hz: Hertz, amount of periods per sec. F: Force in Newton applied on the limb. P: is positioning of the crutch expressed as he ratio between positive and negative deviation of the crutch. 
Design of the instrumented crutch. The crutch in the current study is a standard elbow crutch (RASOULI, 2019; PAPADOSIFOS, 2014). Therefore, an aluminum crutch was therefore the optimal choice, because of its lightness $\left(2.700 \mathrm{~kg} / \mathrm{m}^{3}\right)$, tensile strength $(70-700 \mathrm{MPa})$ and Young's modulus (69 GPa) $(* * * 2015)$.
The prototype included four strain gauges installed as a full Wheatstone bridge. Also, a tri-axial gyroscope and a tri-axial accelerometer (MPU-605) Fig. 2, were used to compute roll (X-axis) and pitch (Y axis) angle. Lastly, the data is sent by Blue-tooth to a developed end-user program made in Python by mean of a microcontroller (ESP32).

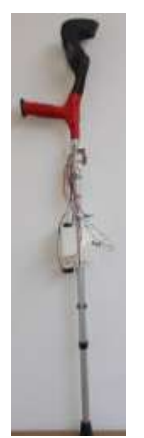

a)

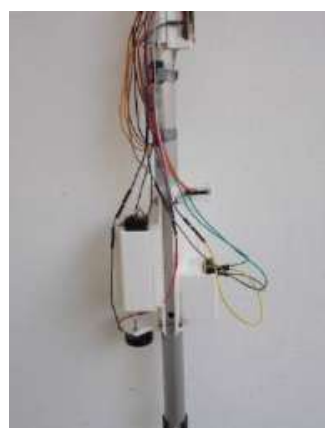

b)

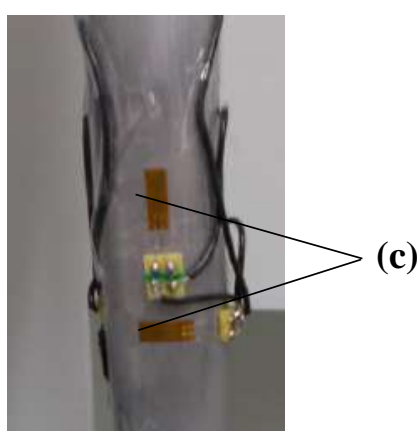

c)

Figure 1. Instrumented crutch with the strain gauges in a Wheatstone configuration (c)
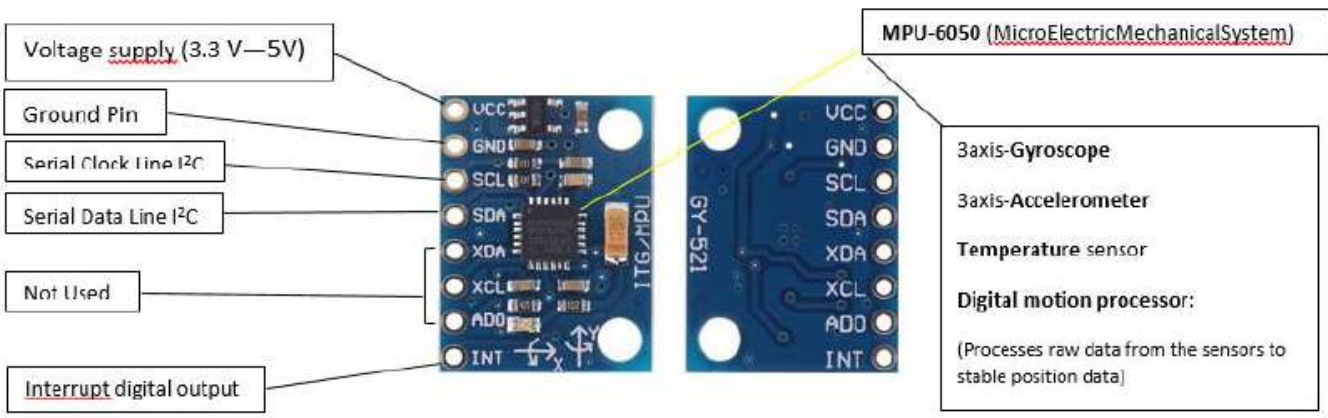

Figure 2. Tri-axial gyroscope and tri-axial accelerometer MEMS MPU 6050.

These data could give the examiner an idea on the cadence (smoothness) of walking expressed as periods in time. We assumed that, with the Lofstrand (LOFSTRAND, 1955) crutch, despite the off-set position of the handle, the torque on the crutch would be minimal (BRINCKMANN, 2016). The proximal cuff of the crutch offers a good support to the forearm, compensating the bending moment on the handle.

Table 2. A summary of components choices for the electronic walking device

\begin{tabular}{|l|l|}
\hline Purpose & Component \\
\hline Microcontroller \& Interface & Arduino Uno \\
\hline Pitch sensing & MPU-6050 Gyroscope/Accelerometer IMU \\
\hline Wireless transmission & ESP32 LoRa \\
\hline Off/On Switch & Rocker Switch \\
\hline Graphic Software & PyCharm version 2019.1.3 (JetBrains Czech ) \\
\hline
\end{tabular}

We chose a two-point contact contralateral crutch gait because this type of support is mostly prescribed at the end of the revalidation period of an orthopedic ailment. With a two-point contact gait, the injured leg is moved forward together with the crutch held in the opposite arm.

The main objectives of the current study was the feasibility or handling of the instrumented crutches. In addition, we wanted to characterize the quality of walking, which was taken into account using the three parameters obtained from the crutch: angular speed of the crutch in the sagittal plane, expressed as cycles per second (Hz), Force (Newton) and Crutch position (Index).
The position of the crutch, was represented by a curve with positive and negative parts. The positive and negative area's under the curve were calculated and presented as an index; the positive area divided by the negative area. An index above 1 means the crutch was leaning away from the body's center, and that, patients were putting more pressure on the crutch. An index of less than 1 means the crutch was kept closer to the midline of the body, with more pressure on the contralateral limb.

The crutch position index is the ratio between the positive area and the negative area of the recorded curve (Fig. 3). 


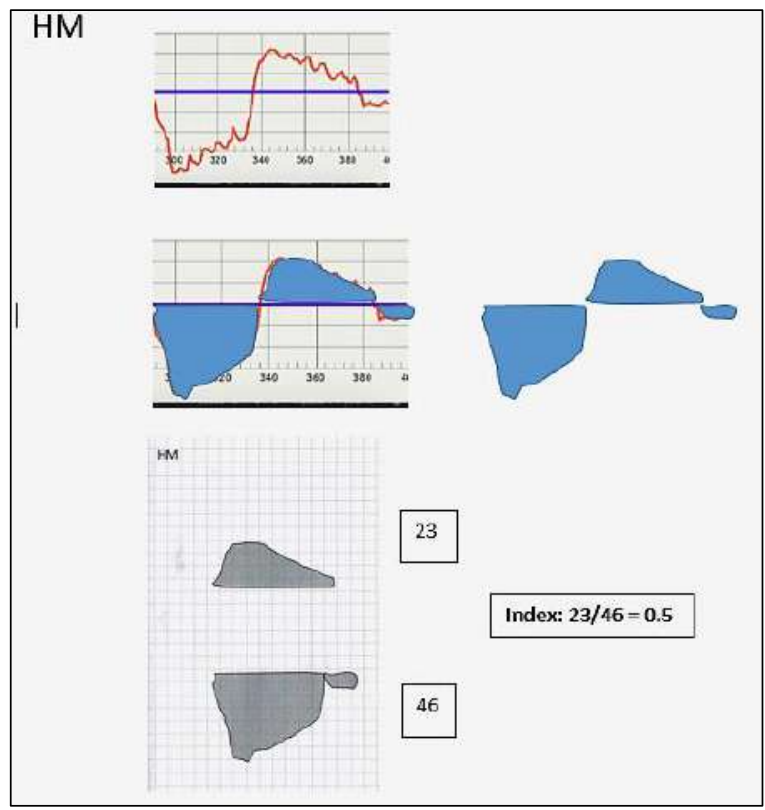

Figure 3. Measuring the area under the curb for positioning of the crutch in the frontal plane.

The rosette strain gauge was glued with isobutyl 2-cyanoacrylate monomer in a well-defined pattern according to the Wheatstone bridge on the surface of the crutch shaft. This Wheatstone bridge pattern is indicated to exclude the measurement of bending moments in the crutch shaft.
In this respect, we assume that the strain gauge deformation on the surface of the crutch shaft reflects those which occurred in the whole crutch shaft.

The data, force, frequency and crutch positions were recorded by a portable computer with Blue-tooth capabilities (Fig. 5).

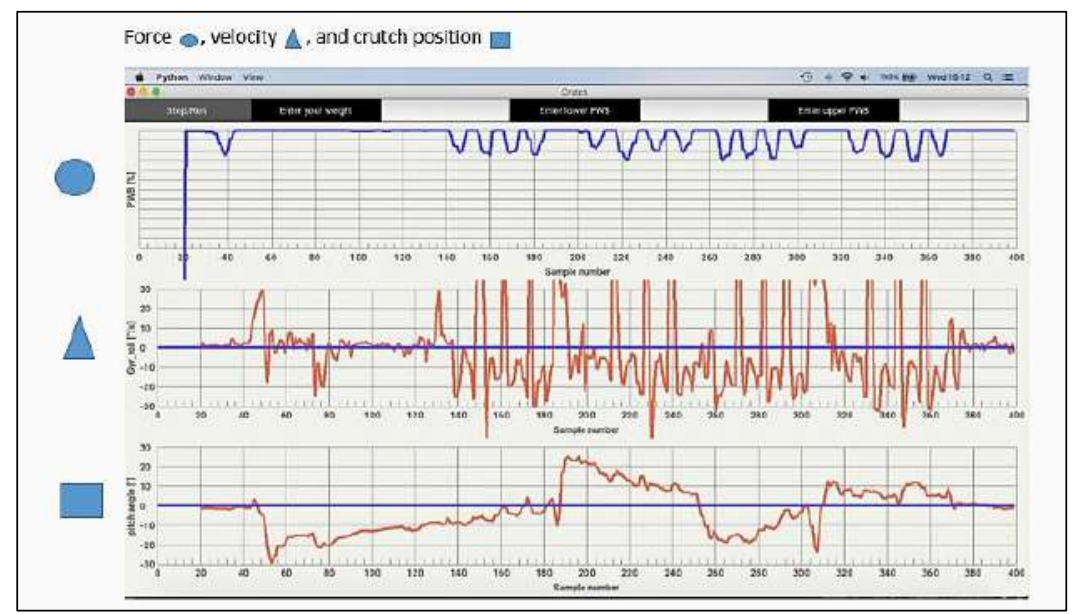

Figure 5. Data obtained from the crutch.

\section{Results}

In all cases we could record the complete data set. We had no technical problems with the crutch.

There were no safety issues.

Force: Mean force exerted on the crutch: $63.7 \mathrm{~N}$ with an $\mathrm{SD}=69.005 \mathrm{~N}$, with a Standard error of mean $=$ 16.73 ---- 95\% Confidence interval, $28.2 \mathrm{~N}---99.1 \mathrm{~N}$

Normality test: Kolmogorov-Smirnoff test 0.2815 $\mathrm{p}$ value $=0.0009$. Passed the normality test: Yes

Hertz: Mean Hz while walking with the crutch $=4.91$, with an SD $=0.807$, with a Standard error of mean $=0.195$,
Median $\left(50^{\text {th }}\right.$ percentile $)=5.2---95 \%$ Confidence interval, 4.5---5.3, Normality test: Kolmogorov-Smirnoff test 0.166 $\mathrm{p}$ value $>0.1$. Passed the normality test: Yes

Position: Position of the crutch: $<1$ means the foot of the crutch is in most of the time away from the base of the feet. Mean position of the crutch $=6.86$, with an SD of 18.9 and a Standard error of mean $=4.59----95 \%$ Confidence interval, -2.8---16.5. Normality test: Kolmogorov-Smirnoff test $0.336 \mathrm{p}$ value $<0.0001$. Passed the normality test: No

There were 10 trials where the volunteer holds the crutch in a positive position (foot of the crutch close to the feet base) and 7 trials where the volunteer holds the crutch 
in a negative position (foot of the crutch away from the base of the feet).

Position of the crutch did not differ statistically between men and female Fischer's exact, two side P value is 1.000 .

We did not find a correlation between force and positioning the crutch: $\mathrm{r}^{2}=0.01860, \mathrm{p}$ value $=0.6017$.

A multiple regression analysis between the force as a constant variable with frequency and position of the crutch (pitch) within the group of volunteers is as follows:

- Force $=32.529+6.187 \times$ V- $0.4981 \times$ Pitch

- $\mathrm{R}^{2}=2.24 \%$ percent of the variance in Force explained by the model.

- P value is 0.8533 and is considered not significant.

- Looking for the significant contribution of one variable, we could not find a variable that contributed to the results significantly.

Before every trial, the crutch was calibrated with a mechanical scale for force on the crutch and with a digital metronome (www.nch.com.au/software) for calibration of pitch and roll and angular speed. In this way, the value obtained by the crutch was substantiated in absolute terms. The linearity between the weight changes on the mechanical scale and the changes of the force curb from the crutch, remained throughout the experiment (one year) which indicates the good bonding between the strain gauge and the crutch shaft.

\section{Discussion}

A major class of research incorporates dynamic aspects of crutch locomotion and includes kinematic measurements. These variables include velocity, displacement, and acceleration in the 3-dimensional planes, ground reaction, gait phase, joint angles. Our study is situated in this group.

We developed an electronic walking device which is remotely connected by Blue-tooth to a portable computer. The electronic crutch was tested by nine able-subjects. Previous scholars recorded the loading as a percent of the total load bearing capacity of a limb (Stallard 1980). The \% PWB is often used to indicate how much weight a patient can bear. In reality, this has little value. In contrast to some authors who stated that overdue weight bearing on the injured leg was possible (Aro 1993), it was never proven that normal patients, without severe proprioceptive deficits, were able to overload and damage healing limbs. Also, the notion of \% PWB is exceedingly difficult to use as a communication tool with physiotherapists. Overall, patients do not understand what it means to load the injured limb to a certain percentage.

Therefore, we adopted another strategy in our pilot study: the real loading of the injured limb was indirectly measured. The calibration of the crutch with a mechanical scale before the walking trials gave us an idea about the loading of the contralateral limb. In combining this new strategy with angular frequency of the crutch movement in the sagittal plane and positioning of the crutch in the frontal plane, we hope to create an algorithm that could characterize the quality of walking. With this algorithm we could express, in percentage, the progress in functional recovery from an orthopedic ailments of the lower limb. We studied three studied parameters: force, angle speed of the crutch in the sagittal plane and crutch position. We did not find any relation between force, age, weight, sex, shoe size and height with the positioning of the crutch in relation with the base of the body. A multiple regression analysis between the force as a constant variable with frequency and position of the crutch (pitch) was done. Looking for the significant contribution of one variable, we could not find a variable that contributed to the results significantly.

Although the results are promising. It is worth noting that:

1. For a healthy volunteer who has no knowledge of crutch handling, it seems rather difficult to learn this. In most other studies, only healthy subjects were used.

Able-body subjects cannot completely demonstrate the walking gait of a disabled crutch user when walking with a crutch due to differences in push-off ability, trunk range of motion, and full usage of shanks and knees (NOREAU, 1995).

2. As we can see from the position of the crutch, this varied from person to person. In the recorded curve of a same person, the position of the crutch could be both positive (upper part of the crutch away from the axis of the person) and negative (upper part of the crutch near to the axis of the person). The index values varied from 0.01 to 79 .

3. The knowledge of loads and inclinations of the crutch can provide valuable information for correct walking. The recorded data can be used for a variety of applications. The previous instrumented crutches were merely developed with an audible biofeedback system that warned the patient when he or she was overloading his or her limbs. The cut-off point for overloading the injured limb is an intuitive process made by the physiotherapist and is merely based on his opinion as an expert (level $\mathrm{V}$ of evidence). As previously mentioned, the patients seemed unable to follow the prescribed instructions on how much to load on the affected limb.

We would like to acknowledge some shortcomings of the study as well. A major drawback was the length of the crutch. Because of the applied equipment of the inbuilt sensors, adapting the length of the crutch to the patient length was difficult. As a general guideline, the length of the crutch should be approximately $75 \%$ of patient's height (KENDALL, 2005; SMIDT, 1980). Because of the lack of sufficient encasing of the hardware around the crutch, the wired crutch became fragile and difficult to use outside the laboratory. Characterizing walking with only three parameters looks futile. Probably, more variables play an important role in walking with a crutch. For example, the damping of loading by proprioception and muscle action could not be incorporated in our model. 


\section{Conclusion}

1. We constructed an instrumented crutch that could record the actual loading of the limbs together with the angle velocity of the crutch in the sagittal plane and position of the crutch in the frontal plane.

2. Future work include comparing two large groups of patients and volunteers to validate the importance of the data gathering by the instrumented crutches.

Also we need to look in for specific orthopedic conditions of the lower leg that could benefit of this diagnostic tool.

Eventually we would like to come to an algorithm, created with the biomechanical data obtained from the crutch that can explain and visualize the functional progress of orthopedic patients.

\section{Acknowledgements}

Permission of the clinical research ethical committee was obtained: CE 2020/90 BUN: B0772020000023

All persons gave informed consent for participating in the study.

\section{References}

1. COURT-BROWN CM, BIANT LC, BUGLER KE, MCQUEEN MM. Changing epidemiology of adult fractures in Scotland. Scott Med J, 2014; 59: 30-4.

2. RÜEDI TP. AO Principles of Fracture Management Thieme: Stuttgart, New York. 2000.

3. ARIZA-VEGA P, KRISTENSEN MT, MARTINMARTIN L, JIMINENEZ-MOLEON JJ. Predictors of Long-Term Mortality in Older People With Hip Fracture. Archives of Physical Medicine and Rehabilitation. 2015 jul; 96(7):1215-1221. Available from: https://www.sciencedirect.com/science/article/ pii/ S0003999315001380

4. KAYE HS, KANG T, LAPLANTE MP. Mobility device use in the United States. Nat Inst Disab Rehab Res., 2000; 14, 1-60 Available at: https://www.researchgate.net/publication/238271865

5. RASOULI F, REED KB. Walking assistances using crutches: A state of the art review. J Biomechanics, 2019; 98, 109489, doi: 10.1016/j.jbiomech.2019. 109489

6. MERRETT GV, ETTABIB MA, PETERS C, HALLETT WHITE NM. Augmenting forearm crutches with wireless sensors for lower limb rehabilitation. Measurement, Sci Tech, 2010; 21, 12, 5-8, https://doi.org/10.1088/0957-0233/21/12/124008

7. MERRETT GV, PETERS C, HALLET G, WHITE NM. An instrumented crutch for monitoring patients' weight distribution during orthopaedic rehabilitation. Procedia Chemistry, 2009; 1, 1, 714-717. Doi:10.1016/ j.proche.2009.07.178

8. TONUTTI M. The Companion Crutch: Design and Development of a Wireless Instrumented Crutch. 2015; CID:00689643, 2015. DOI: 10.13140/RG.2.2.20813. 33763

9. KAHLENBERG CA, NWACHUKWU BU, MCLAWHORN AS, CROSS MB, CORNELL CN, PADGETT DE. Patient satisfaction after total knee replacement: A systematic review. HSS Journal, 2018; 14,7,192-201. doi: 10.1007/s11420-018-9614-8.

10. SARDINI E, SERPELLONI M, LANCINI M, PASINETTI S. Wireless Instrumented Crutches for Force and Tilt Monitoring in Lower Limb Rehabilitation. Procedia Engineering, 2014; 87, 348-351. doi:10.1016/j.proeng.2014.11.745

11. LOFSTRAND ARJ. Crutch. US Patent No. 2.453.632, 1948; Lofstrand ARJ. Crutch. US Patent No. 2.711. $183,1955$.

12. PAPADOSIFOS N. The Complications of Crutches A Summary of a Systematic Review of the Literature, ARG note. 2014; 1, 1-2.

13. *** Aluminium Properties, 2015. Available at: http://www.aluminiumdesign.net/why-aluminium/ properties-ofaluminium. Retrieved 2015, June 15.

14. BRINCKMANN P, FROBIN W, LEIVSETH G. "Orthopedic Biomechanics", Thieme G Pub Stuttgart, 2016. pp. 272-297.

15. STALLARD J, DOUNIS E, MAJOR RE, ROSE GK. One leg swing through gait using two crutches. An analysis of the ground reaction forces and gait phases. Acta Orthop Scand., 1980; 51, 71-77. doi: 10.3109/ 17453678008990771

16. ARO H, CHAO E. Bone-Healing Patterns Affected by Loading, Fracture Fragment Stability, Fracture Type, and Fracture Site Compression. Clin Orthop Relat Res. 1993; 293, 8-17, http://journals.lww.com/corr/Abstract/ 1993/08000/Bone_Healing_Patterns_Affected_by_Lo ading,.3.aspx

17. NOREAU L, RICHARDS CL, COMEAU F, TARDIF D. Biomechanical analysis of swing-through gait in paraplegic and non-disabled individuals. J. Biomech, 1995; 28, 689-700. https://doi.org/10.1016/00219290(94)00118-N

18. KENDALL FP, MCCREARY EK, PROVANCE PG, RODGERS M, ROMANI W. eds. "Muscles Testing and Function, $5^{\text {th }}$ edition". Philadelphia, PA: Lippincott Williams and Wilkins, Philadelphia, 2005, pp. 213-256.

19. SMIDT GL, MOMMENS MA. System of reporting and comparing influence of ambulatory aids on gait. Phys.Ther., 1980; 60, 551-558, https: //doi.org/10.1093/ ptj/60.5.551 